University of Nebraska - Lincoln

DigitalCommons@University of Nebraska - Lincoln

Effect of maternal restraint stress during gestation on temporal lipopolysaccharide-induced neuroendocrine and immune responses of progeny

\author{
C.T. Collier
}

Texas A\&M University

P.N. Williams

Texas A\&M University

J.A. Carroll

USDA-ARS Livestock Issues Research Unit

T.H. Welsh Jr

Texas A\&M University System

J.C. Laurenz

Texas A\&M University, jamie.laurenz@enmu.edu

Follow this and additional works at: https://digitalcommons.unl.edu/usdaarsfacpub

Part of the Agricultural Science Commons

Collier, C.T.; Williams, P.N.; Carroll, J.A.; Welsh, T.H. Jr; and Laurenz, J.C., "Effect of maternal restraint stress during gestation on temporal lipopolysaccharide-induced neuroendocrine and immune responses of progeny" (2011). Publications from USDA-ARS / UNL Faculty. 847.

https://digitalcommons.unl.edu/usdaarsfacpub/847

This Article is brought to you for free and open access by the U.S. Department of Agriculture: Agricultural Research Service, Lincoln, Nebraska at DigitalCommons@University of Nebraska - Lincoln. It has been accepted for inclusion in Publications from USDA-ARS / UNL Faculty by an authorized administrator of DigitalCommons@University of Nebraska - Lincoln. 


\title{
Effect of maternal restraint stress during gestation on temporal lipopolysaccharide-induced neuroendocrine and immune responses of progeny
}

\author{
C.T. Collier ${ }^{\mathrm{a}}$, P.N. Williams ${ }^{\mathrm{a}}$, J.A. Carroll ${ }^{\mathrm{b}}$, T.H. Welsh Jr ${ }^{\mathrm{c}}$, J.C. Laurenz ${ }^{\mathrm{a}, *}$ \\ ${ }^{a}$ Department of Animal and Wildlife Sciences, College of Agriculture and Human Sciences, Texas A\&M University-Kingsville, \\ TX 78363, USA \\ ${ }^{\mathrm{b}}$ USDA-ARS Livestock Issues Research Unit, Lubbock, TX 79403, USA \\ ${ }^{\mathrm{c}}$ Texas AgriLife Research, Texas A\&M University System, College Station, TX 77843, USA
}

Received 1 July 2010; received in revised form 19 August 2010; accepted 21 August 2010

\begin{abstract}
The impact of gestational dam restraint stress on progeny immune and neuroendocrine temporal hormone responses to lipopolysaccharide (LPS) challenge was assessed. Maternal stress (5-min snout snare restraint stress during days 84 to 112 of gestation) increased $(P<0.05)$ the magnitude of tumor necrosis factor (TNF)- $\alpha$, interleukin-6, epinephrine (E), norepinephrine, and serum amyloid A (SAA) production following LPS infusion in the offspring. Moreover, these effects appear to be dependent on gender for TNF- $\alpha$, E, and cortisol production. However, maternal stress did not affect $(P>0.05)$ the normalization of proinflammatory cytokines or neuroendocrine hormones produced following LPS. Collectively, these results indicate that maternal stress impacts aspects of the proinflammatory cytokine and stress hormone response in their progeny following LPS dosing of the offspring. This response is potentially responsible in part for the resultant changes to SAA production. Because several of the changes observed here are dependent on pig gender, these results are also the first evidence that inherent epigenetic factors coupled with maternal stress impact the cumulative response to stress and LPS in young pigs.
\end{abstract}

(C) 2011 Elsevier Inc. All rights reserved.

Keywords: Cytokine; Gender; Lipopolysaccharide; Maternal stress; Pig

\section{Introduction}

Routine swine industry management procedures such as restraint, transportation, and changes in housing conditions can be stressful for gestating sows and cause

Mention of trade names or proprietary products does not constitute a guarantee or warranty of the product by the USDA and does not imply its approval to the exclusion of other products that may also be suitable.

* Corresponding author. ENMU Station 2, 1500 S Ave K, Portales, NM 88130, USA. Tel: 575-562-2312.

E-mail address: jamie.laurenz@enmu.edu (J.C. Laurenz). activation of the hypothalamic-pituitary-adrenal (HPA) axis [1-3]. The resultant maternal glucocorticoid release can cross the placenta in pigs [4] and may exert secondary effects on fetal development. Stress of this nature is termed maternal or prenatal stress [2]. The influence of maternal glucocorticoid on fetal HPA axis development may also affect function of this axis throughout the life of the progeny [3,5]. Specifically, maternally stressed offspring could have an HPA axis primed to be hyperactive to stressors and the subsequent altered production of stress-related hormones would adversely affect growth, health, reproduction, and the general welfare of 
the animal. There is evidence that maternal reprogramming of the progeny's HPA axis can influence the in vitro response of their immune cells [6,7]. Whereas effects of maternal stress on the HPA axis of the offspring have been documented, little information is available concerning the effect of maternal stress on the activity of the sympathetic nervous system and concomitant release of adrenal catecholamines. There is also little evidence detailing the impact of maternal stress on the immune and stress responses to an in vivo immune challenge of the offspring. Because previous results from this lab suggest temporal and gender effects on LPS-induced stress hormone and cytokine responses [8], the present report describes the effects of maternal stress on immune and stress responses of male and female progeny to in vivo LPS administration.

\subsection{Materials and methods}

\subsection{Animals and experimental design}

All experimental procedures were in accordance with the Guide for the Care and Use of Agriculture Animals in Agricultural Research and Teaching and approved by the Institutional Animal Care and Use Committee of Texas A\&M University, Kingsville. The effects of maternal stress on stress response and immune function in offspring were evaluated. The sows were housed in gestation stalls, fed once daily, and allowed ad libitum access to water throughout gestation according to standard practices at the Texas Tech University Swine Farm. Sows were assigned to one of two treatment groups: nonstressed or stressed. The sows assigned to the stress treatment were subjected to restraint stress for $5 \mathrm{~min}$ each day from weeks 12 to 16 (days 84 to 112) of gestation. Restraint of the sow was performed using a nose sling composed of a soft cotton material. Control sows continued through gestation without treatment. On day 112 of gestation, the sows were moved into farrowing crates. After farrowing (within $24 \mathrm{~h}$ ), the pigs were processed according to standard practices at the Texas Tech University Swine Farm (needle teeth clipped, tail docked, ear notches for identification, and any males were castrated). At weaning (20.0 $\pm 0.3 \mathrm{~d}$ of age) 2 barrows (B) and 2 gilts (G) from each of 10 control (nonstressed, NS) and 10 stressed litters ( $\mathrm{S} ; 40$ pigs per experimental group, $\mathrm{n}=$ 80 overall) were taken to the Livestock Issues Research Unit's nursery facility.

Pigs were weighed, placed in individual pens $(1.2 \mathrm{~m}$ $\times 0.6 \mathrm{~m})$, and allowed ad libitum access to food and water. The pigs were given $14 \mathrm{~d}$ to adjust to their surroundings and diet. All pigs were weighed and nonsurgically fitted with an indwelling jugular catheter according to Carroll et al [9] $1 \mathrm{~d}$ prior to lipopolysaccharide (LPS) infusion. Pigs were then given $24 \mathrm{~h}$ to recover from the cannulation procedure before blood collection began. Prior to the first sample, an extension was attached to the catheter to allow for remote sampling without handling of the pigs. Blood samples were taken every $30 \mathrm{~min}$ from $1 \mathrm{~h}$ before to $6 \mathrm{~h}$ after LPS infusion (Escherichia coli 0111:B4; Sigma L-2630, Sigma Chemical, St Louis, MO, USA; $25 \mu \mathrm{g} / \mathrm{kg}$ body weight). Approximately $5 \mathrm{~mL}$ of blood was drawn at each time point into a serum tube, allowed to clot for $1 \mathrm{~h}$ at room temperature, centrifuged at $1400 \mathrm{~g}$ for 20 min at $20{ }^{\circ} \mathrm{C}$, serum collected into microcentrifuge tubes, and then stored at $-80{ }^{\circ} \mathrm{C}$ for later analysis. Total white blood cell and white blood cell differential counts were performed on whole blood samples taken at $-0.5,5.5$, and $24 \mathrm{~h}$ using a Cell-Dyn differential analyzer (Abbott Laboratories; Abbott Park, IL, USA).

\subsection{Serum analysis}

The serum concentration of cortisol was determined in duplicate using a commercially available Coat-a-Count assay kit (Diagnostic Products Corp; Los Angeles, CA, USA). Serum concentrations of epinephrine (E) and norepinephrine $(\mathrm{pg} / \mathrm{mL})$ were determined using an EIA kit (Tri-Cat-EIA; American Laboratory Products Company, Windham, NH, USA) per the manufacturer's directions. The concentration of serum cytokines (tumor necrosis factor (TNF)- $\alpha$, interleukin (IL)- $1 \beta$, interferon gamma, and IL-6) was determined according to the manufacturer's protocol using a porcine-specific enzymelinked immunosorbent assay kit for proinflammatory cytokines (SearchLight Porcine Inflammatory Cytokine Array No. 84664; Pierce, Rockford, IL, USA). The acute phase proteins serum amyloid A (SAA), C-reactive protein (CRP), and haptoglobin were also analyzed with commercially available kits (Tridelta Phase Range serum amyloid A, C-reactive protein, and haptoglobin assays; Tridelta Diagnostic Products Inc, Morris Plains, NJ, USA). All assays were performed in duplicate and intra- and interassay coefficient of variance $(\mathrm{CV})$ values were calculated. The intra- and interassay CV were less than $8 \%$ and $9 \%$, respectively, for cytokine analyses and $11 \%$ and $12 \%$, respectively, for the catecholamines. For acutephase proteins (APPs), the intra- and interassay CV were less than $7 \%$ and $6 \%$, respectively. 


\subsection{Statistical analysis}

Calculations for the area under the curve (AUC) were determined using the trapezoid method of SigmaPlot (Systat Software, Inc, San Jose, CA, USA). All data were subjected to analysis of variance specific for repeated measures using the mixed procedure of SAS (SAS Institute, Inc, Cary, NC, USA). Sources of variation included, sow, maternal treatment, time, sex, and their interactions. Specific treatment comparisons were made using Fisher's protected least significant difference test with comparisons of $P<0.05$ considered significant. Pearson's correlation coefficients were determined among either the magnitude of responses (peak concentrations) or the duration of the responses (AUC).

\section{Results}

\subsection{Proinflammatory cytokines}

Prior to LPS ( -1 to $0 \mathrm{~h}$ ), NS animals had higher $(P<0.01)$ basal serum TNF- $\alpha$ concentration than $\mathrm{S}$ animals $(7.4 \pm 0.6$ vs. $5.1 \pm 0.6 \mathrm{pg} / \mathrm{mL}$, respectively). As expected, LPS induced a time-dependent increase $(P<0.01)$ in TNF- $\alpha$ with initial increases apparent by $0.5 \mathrm{~h}$ post-LPS and peak concentration occurring at $1 \mathrm{~h}$ post-LPS (Fig. 1). Serum TNF- $\alpha$ then decreased for the remainder of the sampling period, reaching baseline concentration (i.e. pre-LPS) by $5 \mathrm{~h}$ post-LPS. Peak concentration was influenced by the main effect of sex $(P<0.06)$ with $\mathrm{B}$ having a higher concentration of TNF- $\alpha$ than G $(736 \pm 37$ vs. $640 \pm 37$ pg/mL, respectively). The overall temporal pattern was not affected by maternal treatment; however, a sex $\times$ maternal treatment interaction did exist $(P<0.05)$ with $\mathrm{S} B$ having a lower $(P<0.05)$ peak concentration than NS B $(2819 \pm 200$ vs. $3378 \pm 190 \mathrm{pg} / \mathrm{mL}$, respectively). In contrast, peak concentration did not differ $(P=0.21)$ between NS G and S G. However, the temporal pattern of TNF- $\alpha$ production was similar in both maternal treatments $(P=0.99)$ and neither maternal treatment $(P=0.71)$ nor sex $(P=0.11)$ affected the duration of exposure to TNF- $\alpha$ as measured by AUC $(4,404 \pm 328$ and 4,577 \pm 342 for NS and S, respectively; 4,865 \pm 333 and 4,115 \pm 338 for B and G, respectively). There was a tendency $(P=0.08)$ for a sex $\times$ maternal treatment interaction on the duration of exposure to TNF- $\alpha$, because NS B tended to have a higher AUC than S B, whereas S G tended to have a higher AUC than NS G $(5,197 \pm 458$ vs. $4,534 \pm 483$ for NS B and
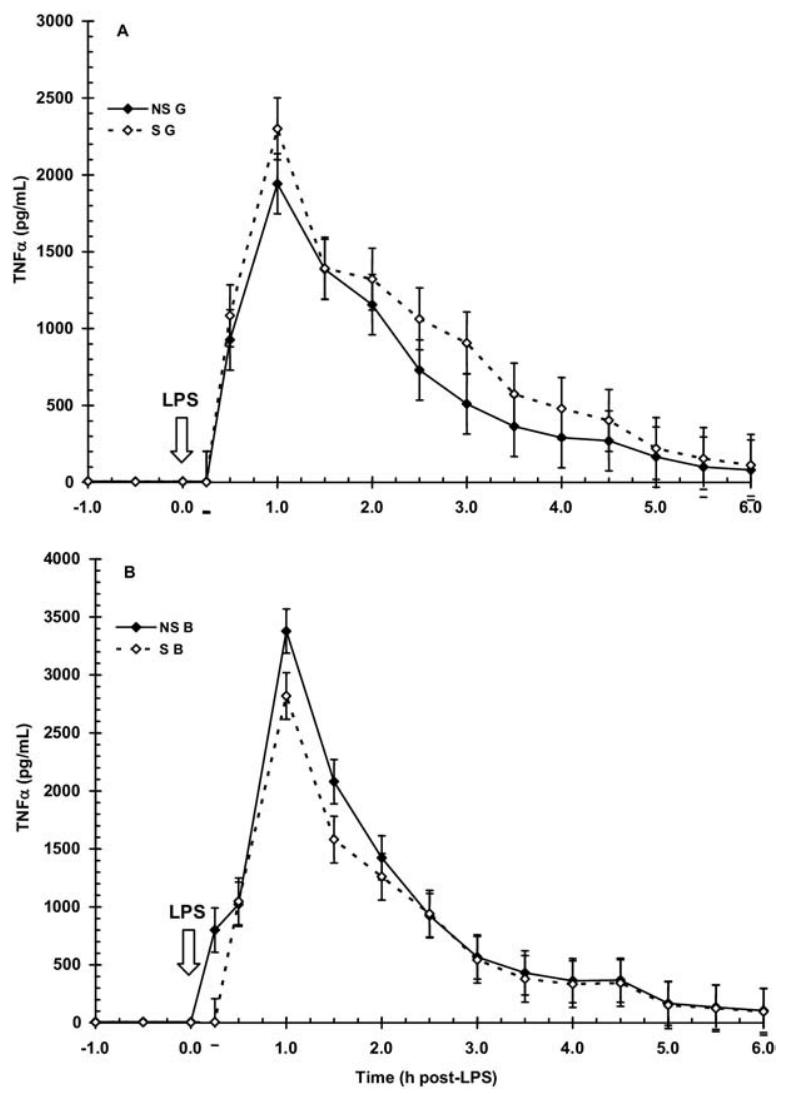

Fig. 1. Effect of maternal stress on the serum TNF- $\alpha$ response of pigs to an intravenous challenge with $25 \mu \mathrm{g} / \mathrm{kg}$ LPS. Pigs were obtained from sows either subjected to a daily 5-min restraint stress (stressed; S) from days 84 to 112 of gestation or managed per current industry standards (nonstressed; NS). Values represent the mean \pm SEM for (A) gilts (NS G and $\mathrm{S} G, \mathrm{n}=19$ and 18 , respectively) and (B) barrows (NS B and S B; n $=20$ and 20, respectively). Peak TNF- $\alpha$ concentration was influenced by the main effect of sex $(P<0.06)$ with $\mathrm{B}$ having a higher $(P<0.05)$ concentration of TNF- $\alpha$ than G.

$S$ B, respectively, and 4,619 \pm 486 vs. 3,610 \pm 471 for S G and NS G, respectively).

The concentration of serum IL- $1 \beta(37 \pm 1 \mathrm{pg} / \mathrm{mL})$ prior to LPS ( -1 to $0 \mathrm{~h})$ was not affected by $\operatorname{sex}(P=$ $0.78)$ or maternal treatment $(P=0.96)$. Lipopolysaccharide induced a time-dependent increase $(P<0.01)$ in IL-1 $\beta$ concentration with an initial increase apparent by $1.5 \mathrm{~h}$ post-LPS and a peak concentration occurring at $3 \mathrm{~h}$ post-LPS (Fig. 2). Serum IL-1 $\beta$ then steadily decreased but, unlike TNF- $\alpha$, remained elevated above baseline throughout the 6-h post-LPS sampling period. There was no influence of maternal treatment $(P=$ $0.71)$ or sex $(P=0.34)$ on IL-1 $\beta$ production following LPS. Similarly, maternal treatment did not influence the temporal pattern $(P=1.0)$ or the duration of exposure 


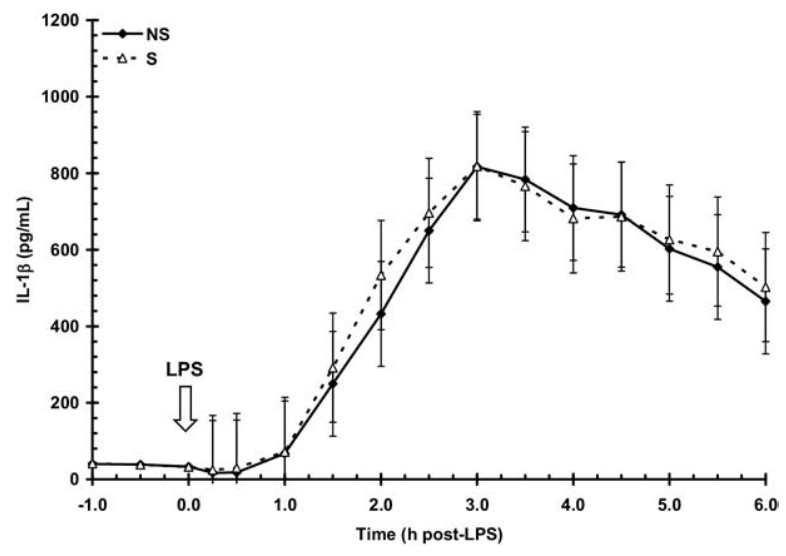

Fig. 2. Effect of maternal stress on the serum IL-1 $\beta$ response of pigs to an intravenous challenge with $25 \mu \mathrm{g} / \mathrm{kg}$ LPS. Pigs were obtained from sows either subjected to a daily 5-min restraint stress (stressed; S) from days 84 to 112 of gestation or managed per current industry standards (nonstressed; NS). Values represent the mean \pm SEM (NS, $\mathrm{n}=39 ; \mathrm{S}, \mathrm{n}=36)$. There was no influence of maternal treatment $(P=0.71)$ or $\operatorname{sex}(P=0.34)$ on IL-1 $\beta$ production following LPS.

to IL-1 $\beta$ (AUC $=2,362 \pm 623$ and $2,452 \pm 650$ for NS and $\mathrm{S}$, respectively; $P=0.92)$. There was also no influence of sex on the temporal pattern $(P=0.99)$ or duration of IL-1 $\beta$ exposure $(P=0.67$; $\mathrm{AUC}=2,218 \pm$ 631 and 2,596 \pm 642 for $\mathrm{B}$ and $\mathrm{G}$, respectively).

Basal serum IL-6 concentration prior to LPS ( -1 to $0 \mathrm{~h})$ was greater $(P<0.05)$ in NS than in $\mathrm{S}$ animals (87 \pm 9 vs. $56 \pm 9$ pg/mL, respectively). Lipopolysaccharide induced a time-dependent increase $(P<0.01)$ in serum IL-6 with an initial increase apparent by $1.5 \mathrm{~h}$ post-LPS and peak concentration occurring at $2.5 \mathrm{~h}$ post-LPS (Fig. 3). Serum IL-6 then began to decrease and approached baseline concentration by the end of the 6 -h post-LPS sampling period. Serum IL-6 postLPS was influenced by maternal treatment $(P<0.01)$ with $\mathrm{S}$ pigs having a higher overall response than NS $(506 \pm 30$ vs. $374 \pm 29 \mathrm{pg} / \mathrm{mL}$, respectively) and a higher $(P<0.05)$ magnitude of response $(1,312 \pm 114$ vs. $1,002 \pm 110 \mathrm{pg} / \mathrm{mL}$ for $\mathrm{S}$ and NS, respectively). The main effect of sex $(P<0.05)$ also influenced the IL-6 response to LPS, with G having a higher overall response than B in both NS and S pigs (485 \pm 30 vs. $395 \pm 29 \mathrm{pg} / \mathrm{mL}$ for $\mathrm{G}$ and $\mathrm{B}$, respectively). However, similar to IL- $1 \beta$, the temporal pattern of IL- 6 post-LPS was not influenced by maternal treatment $(P=0.60)$ or sex $(P=0.94)$. Duration of exposure to IL-6 was similar in both maternal treatments $(2,429 \pm 457$ and $2,370 \pm 476$ for NS and S, respectively; $P=0.20$ ) and sexes $(2,571 \pm 463$ and $3,128 \pm 470$ for $B$ and $G$, respectively; $P=0.40$ ).
Serum interferon gamma concentration prior to LPS ( -1 to $0 \mathrm{~h}$ ) was similar $(P=0.06)$ between NS and $\mathrm{S}$ animals $(90 \pm 11$ vs. $61 \pm 11 \mathrm{pg} / \mathrm{mL}$, respectively). Lipopolysaccharide induced a time-dependent increase $(P<0.01)$ in serum interferon gamma, with an initial increase apparent at $2 \mathrm{~h}$ and peak concentration occurring at $2.5 \mathrm{~h}$ post-LPS (Fig. 4). The interferon gamma response was not affected by sex $(P=0.55)$ or maternal treatment $(P=0.11)$. The temporal pattern for the interferon gamma response was not influenced by maternal treatment $(P=0.63)$ or sex $(P=0.94)$. The duration of exposure to interferon gamma was not influenced by maternal treatment $(\mathrm{AUC}=910 \pm 175$ and $1,089 \pm 182$ for NS and S, respectively; $P=0.48$ ) or sex $(1,018 \pm 177$ and $981 \pm 180$ for $B$ and $G$, respectively; $P=0.88$ ).

Correlation analysis indicated strong positive relationships between the duration of the cytokine responses (AUC), including IL- $1 \beta$ and IL-6 $(\mathrm{r}=0.76$, $P<0.01)$, IL-1 $\beta$, and interferon gamma $(\mathrm{r}=0.66, P<$ 0.01 ). Similarly, there were positive relationships between the duration of the TNF- $\alpha$ and IL-6 and the TNF- $\alpha$ and interferon gamma responses following LPS ( $\mathrm{r}=0.52$ and $0.43, P<0.01$, respectively). These relationships were not influenced by maternal treatment. However, positive relationships between the duration of the TNF- $\alpha$ and IL- $1 \beta$ responses were found

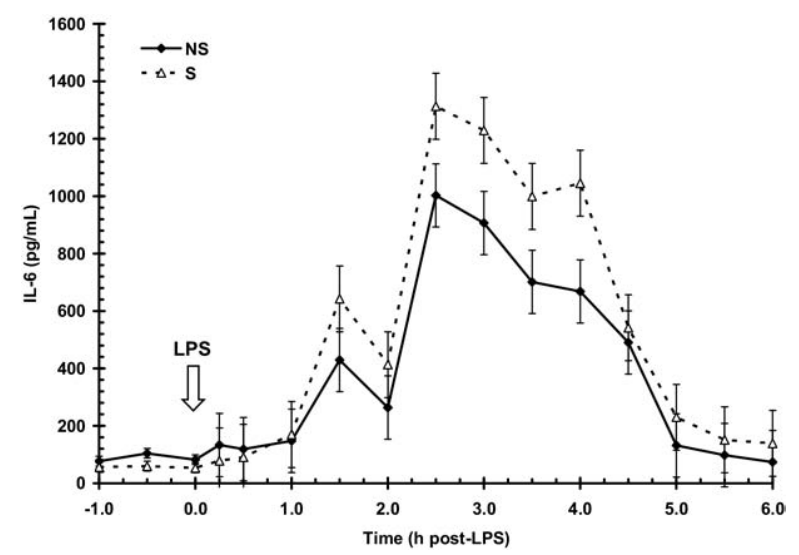

Fig. 3. Effect of maternal stress on the serum IL-6 response of pigs to an intravenous challenge with $25 \mu \mathrm{g} / \mathrm{kg}$ LPS. Pigs were obtained from sows either subjected to a daily 5-min restraint stress (stressed; S) from days 84 to 112 of gestation or managed per current industry standards (nonstressed; NS). Values represent the mean \pm SEM $(n=$ $39 \mathrm{NS}$ and $\mathrm{n}=36 \mathrm{~S})$. Serum IL-6 post-LPS was influenced by maternal treatment $(P<0.01)$ with $\mathrm{S}$ pigs having a higher overall response than NS and a higher $(P<0.05)$ magnitude of response. The main effect of $\operatorname{sex}(P<0.05)$ also influenced the IL-6 response to LPS, with G having a higher overall response than B in both NS and $\mathrm{S}$ pigs. 


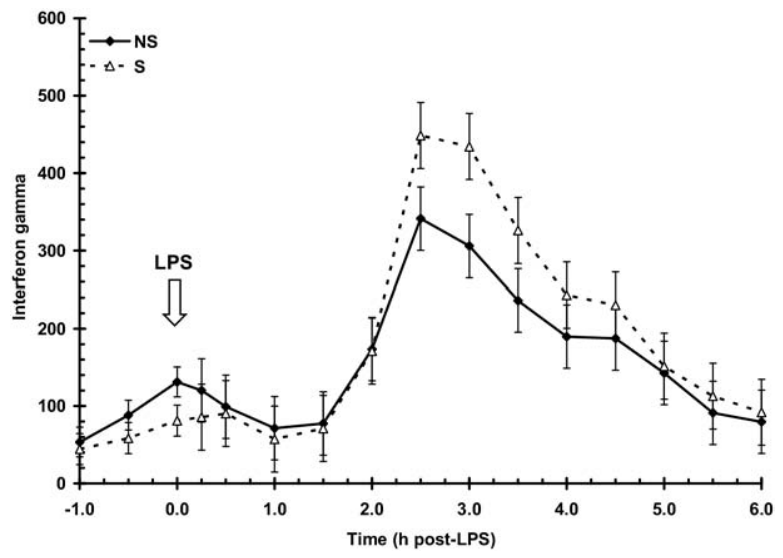

Fig. 4. Effect of maternal stress on the serum interferon gamma response of pigs to an intravenous challenge with $25 \mu \mathrm{g} / \mathrm{kg}$ LPS. Pigs were obtained from sows either subjected to either a daily 5-min restraint stress (stressed, S) from days 84 to 112 of gestation or managed per current industry standards (nonstressed, NS). Values represent the mean $\pm \operatorname{SEM}(\mathrm{n}=39 \mathrm{NS}$ and $\mathrm{n}=36 \mathrm{~S})$. The interferon gamma response was not affected by sex $(P=0.55)$ or maternal treatment $(P=0.11)$.

only in NS pigs ( $\mathrm{r}=0.28, P<0.05$, vs. $\mathrm{r}=0.18, P=$ 0.28 , for NS vs. S pigs, respectively).

\subsection{Stress hormones}

Basal serum cortisol concentration prior to LPS (-1 to $0 \mathrm{~h})$ was greater $(P<0.05)$ in $\mathrm{S}$ pigs when compared with NS pigs ( $24 \pm 1$ vs. $19 \pm 1 \mathrm{ng} / \mathrm{mL}$, respectively). As expected, LPS induced a time-dependent increase $(P<0.01)$ in cortisol, with an initial increase apparent by $0.5 \mathrm{~h}$ and peak concentration occurring at $2.5 \mathrm{~h}$ post-LPS (Fig. 5). Serum cortisol then decreased for the remainder of the 6-h sampling period, but did not return to basal concentration (i.e. pre-LPS). There was a main effect of maternal treatment $(P<0.01)$ with NS pigs having a higher overall cortisol response to LPS than S

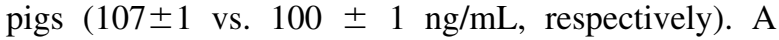
sex $\times$ maternal treatment interaction $(P<0.05)$ was evident, with $\mathrm{S}$ B having a reduced $(P<0.01)$ magnitude of cortisol response following LPS compared with NS B $(127 \pm 7$ vs. $161 \pm 7 \mathrm{ng} / \mathrm{mL}$, respectively), whereas S G and NS G had similar peak concentrations of cortisol following LPS. However, the temporal pattern of cortisol response following LPS was similar in both maternal treatments and sexes $(P=0.29$ and 0.93 , respectively). Furthermore, the duration of exposure to cortisol was not influenced by maternal treatment $(\mathrm{AUC}=591 \pm 24$ and $547 \pm 25$ for NS and S pigs, respectively; $P=0.20)$ or sex $(\mathrm{AUC}=577 \pm 24$ and $561 \pm 24$ for $\mathrm{B}$ and $\mathrm{G}$, respectively; $P=0.63$ ).
Prior to LPS ( -1 to $0 \mathrm{~h}$ ), the serum concentration of $\mathrm{E}$ was higher $(P<0.01)$ in $\mathrm{G}$ than in $\mathrm{B}(100 \pm 5$ vs. $57 \pm 5 \mathrm{pg} / \mathrm{mL}$, respectively). Lipopolysaccharide induced a time-dependent increase $(P<0.01)$ in $\mathrm{E}$, with initial increase apparent by $0.25 \mathrm{~h}$ and peak concentration occurring at 0.5 to $1 \mathrm{~h}$ post-LPS (Fig. 6). The serum concentration of $\mathrm{E}$ decreased following peak and by the end of the sampling period concentrations were approaching baseline. There was a main effect of maternal treatment $(P<0.05)$ on serum E following LPS, with $\mathrm{S}$ pigs having a higher peak concentration of $\mathrm{E}$ at $1 \mathrm{~h}$ post-LPS than NS $(712 \pm 43$ vs. $582 \pm 42 \mathrm{pg} / \mathrm{mL}$, respectively). Serum $\mathrm{E}$ concentration following LPS was also influenced by sex $(P<0.01)$, with $\mathrm{G}$ having
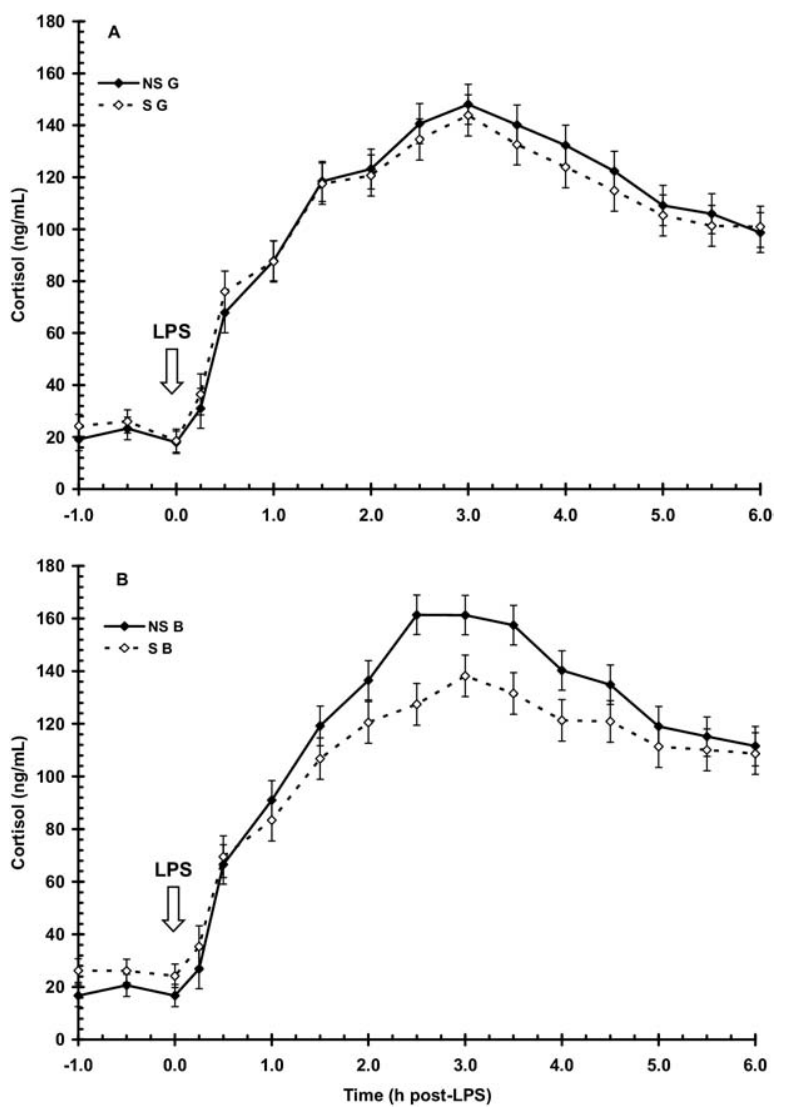

Fig. 5. Effect of maternal stress on the serum cortisol response of pigs to an intravenous challenge with $25 \mu \mathrm{g} / \mathrm{kg}$ LPS. Pigs were obtained from sows either subjected to a daily 5-min restraint stress (stressed; S) from days 84 to 112 of gestation or managed per current industry standards (nonstressed; NS). Values represent the mean \pm SEM for (A) gilts (NS G and $\mathrm{S} G, \mathrm{n}=19$ and 18, respectively) and (B) barrows (NS B and S B; $\mathrm{n}=20$ and 20, respectively). There was a main effect of maternal treatment $(P<0.01)$ with NS pigs having a higher overall cortisol response to LPS than $\mathrm{S}$ pigs. 

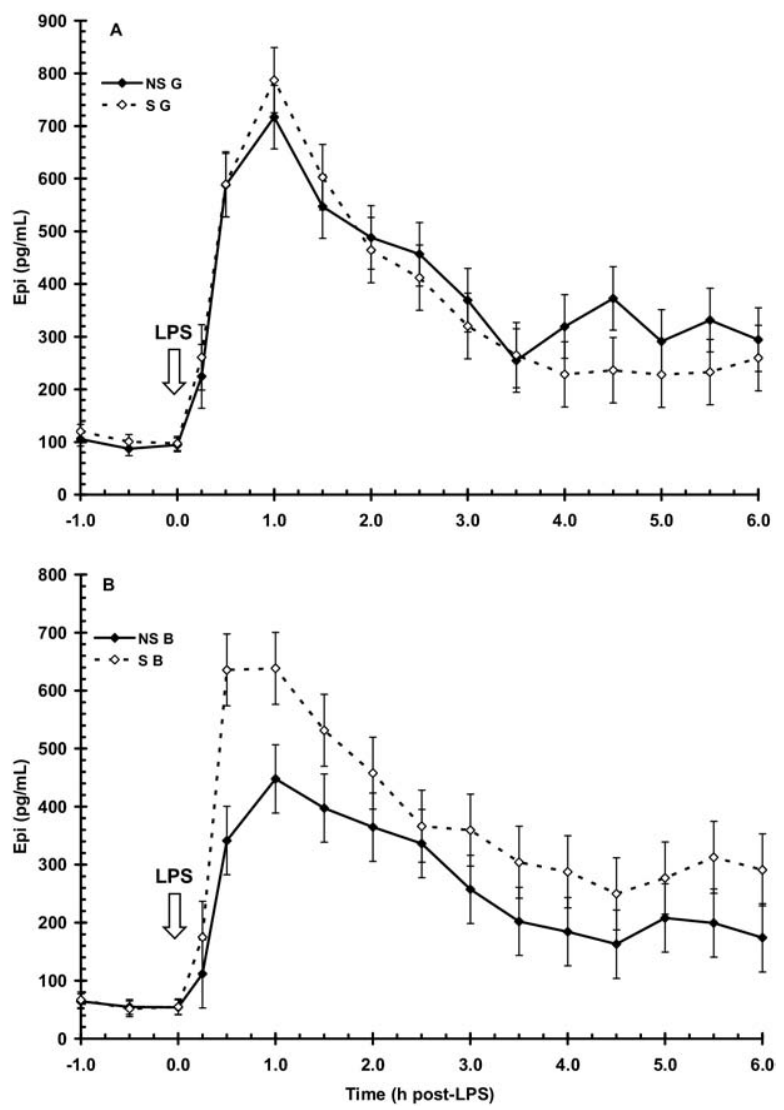

Fig. 6. Effect of maternal stress on the serum E response of pigs to an intravenous challenge with $25 \mu \mathrm{g} / \mathrm{kg}$ LPS. Pigs were obtained from sows either subjected to a daily 5-min restraint stress (stressed; S) from days 84 to 112 of gestation or managed per current industry standards (nonstressed; NS). Values represent the mean \pm SEM for (A) gilts (NS G and $\mathrm{S} G, \mathrm{n}=19$ and 18, respectively) and (B) barrows (NS B and S B; $\mathrm{n}=20$ and 20, respectively). There was a main effect of maternal treatment $(P<0.05)$ on serum $\mathrm{E}$ following LPS, with $S$ pigs having a higher peak concentration of $E$ at $1 \mathrm{~h}$ post-LPS than NS. Serum E concentration following LPS was also influenced by $\operatorname{sex}(P<0.01)$, with $\mathrm{G}$ having a higher overall $\mathrm{E}$ response.

a higher overall $\mathrm{E}$ response $(372 \pm 11$ vs. $299 \pm 11$ $\mathrm{pg} / \mathrm{mL}$ for $\mathrm{G}$ and $\mathrm{B}$, respectively).

Similar to cortisol, serum E response to LPS was also influenced by a sex $\times$ maternal treatment interaction, with $\mathrm{S}$ B having a higher $(P<0.01)$ magnitude of response at $1 \mathrm{~h}$ post-LPS $(638 \pm 62$ vs. $447 \pm 58$ $\mathrm{pg} / \mathrm{mL}$ for $\mathrm{S} B$ vs. NS B, respectively). However, the magnitude of response in $\mathrm{S} \mathrm{G}$ and NS G was similar $(P>0.05)$. As with cortisol, neither maternal treatment $(P=0.72)$ nor sex $(P=0.83)$ affected the temporal pattern of E post-LPS. The duration of exposure to $\mathrm{E}$ following LPS was not affected by maternal treatment
$(\mathrm{AUC}=1,784 \pm 180$ and $1,980 \pm 187$ for $\mathrm{NS}$ and $\mathrm{S}$, respectively; $P=0.45$ ).

Serum NE concentration prior to LPS ( -1 to $0 \mathrm{~h}$ ) was $1,024 \pm 47 \mathrm{pg} / \mathrm{mL}$ and was not influenced by maternal treatment $(P=0.23)$ or $\operatorname{sex}(P=0.20)$. LPS induced a time-dependent increase $(P<0.01)$ in NE with an initial increase and peak concentration occurring by $0.5 \mathrm{~h}$ post-LPS (Fig. 7). Serum NE then rapidly decreased $(P<0.01)$ and approximated the basal concentration for the remainder of the sampling period. There was no main effect of maternal treatment or sex on the NE response following LPS $(P=0.28$ and 0.70 , respectively). However, there was a sex $\times$ maternal treatment interaction $(P<0.05)$, with $\mathrm{S} \mathrm{B}$ having a higher peak concentration of NE than NS B $(2,187 \pm$
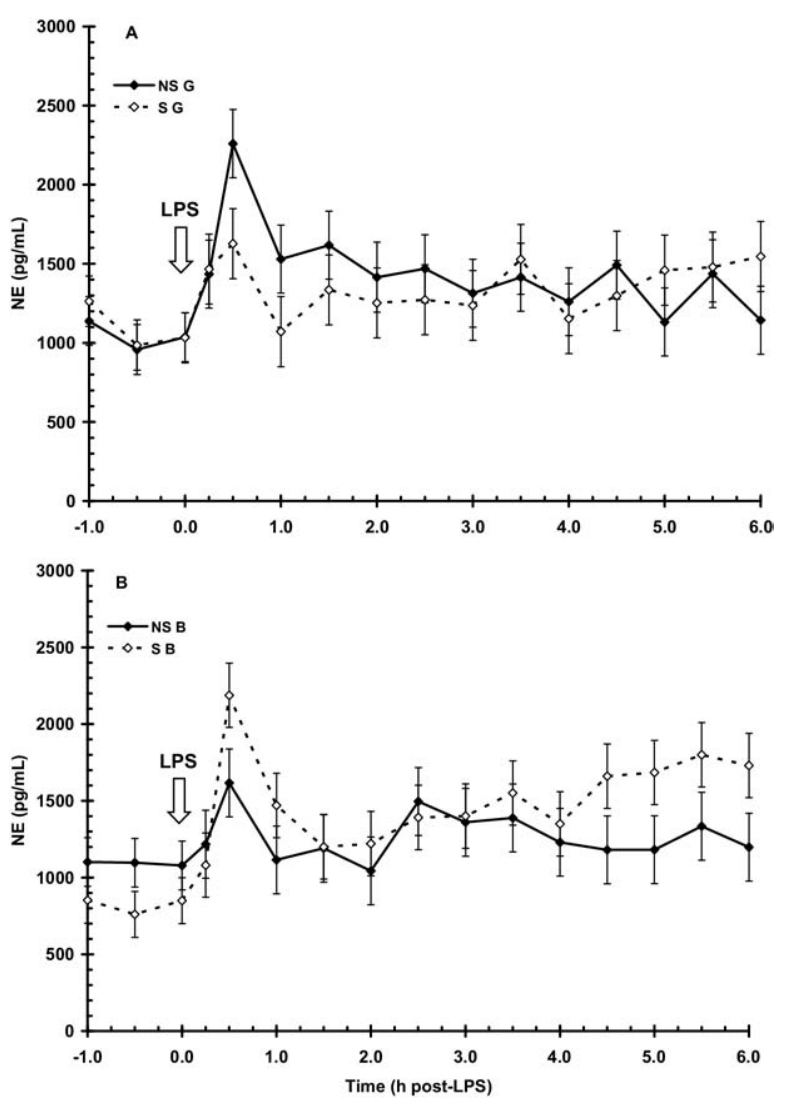

Fig. 7. Effect of maternal stress on the serum NE response of pigs to an intravenous challenge with $25 \mu \mathrm{g} / \mathrm{kg}$ LPS. Pigs were obtained from sows either subjected to either a daily 5-min restraint stress (stressed; S) from days 84 to 112 of gestation or managed per current industry standards (nonstressed; NS). Values represent the mean \pm SEM for (A) gilts (NS G and S G, n = 19 and 18, respectively) and (B) barrows (NS B and S B; $\mathrm{n}=20$ and 20, respectively). There was no main effect of maternal treatment or sex on the NE response following LPS $(P=0.28$ and 0.70 , respectively). 
220 vs. $1,616 \pm 209 \mathrm{pg} / \mathrm{mL}$, respectively), whereas NS $\mathrm{G}$ had a higher peak concentration of NE than $\mathrm{S} \mathrm{G}$ $(2,259 \pm 215$ vs. $1,626 \pm 221 \mathrm{pg} / \mathrm{mL}$, respectively $)$. Similar to the other stress hormones, there was no main effect of maternal treatment (AUC $=6,834 \pm 588$ and $6,913 \pm 613$ for NS and S, respectively; $P=0.92$ ) or $\operatorname{sex}(6,791 \pm 595$ and $6,955 \pm 605$ for $B$ and $G$, respectively; $P=0.84$ ) on the duration of exposure to NE following LPS.

Correlation analysis indicated a positive relationship between the magnitude of the $\mathrm{E}$ and NE response following LPS ( $\mathrm{r}=0.39, P<0.01)$ that was not affected by maternal treatment. In contrast, there was a negative relationship between the magnitude of the NE and cortisol responses following LPS that was present in S pigs $(\mathrm{r}=-0.33, P<0.05)$ but not in NS pigs $(\mathrm{r}=-0.14$, $P=0.39$ ). A relationship between the magnitude of the $\mathrm{E}$ and cortisol responses following LPS was not observed ( $\mathrm{r}=-0.11, P=0.36$ ), regardless of maternal treatment. Correlation analysis also indicated a positive relationship between the duration of the $\mathrm{E}$ and $\mathrm{NE}$ responses following LPS $(\mathrm{r}=0.52, P<0.01)$ that was not influenced by maternal treatment. There were no relationships found between the duration of the cortisol and $\mathrm{E}$ responses $(\mathrm{r}=0.02, P=0.80)$ or cortisol and NE responses $(r=-0.13, P=0.25)$, regardless of maternal treatment. Positive relationships were also observed between the magnitude of the IL-1 $\beta$ and $\mathrm{E}$ responses $(\mathrm{r}=0.56, P<0.01)$ and the magnitude of the IL- 6 and E responses $(\mathrm{r}=0.52, P<0.01)$ following LPS that were not influenced by maternal treatment. There was also a positive relationship between the magnitude of the IL- 6 and NE responses $(r=0.27, P<$ $0.05)$. A positive relationship was also found between the magnitude of the IL- $1 \beta$ and NE responses following LPS in NS pigs $(\mathrm{r}=0.41, P<0.01)$ that was not present in $\mathrm{S}$ pigs $(\mathrm{r}=0.13, P=0.44)$. In contrast, there was a positive relationship between the magnitude of the interferon gamma and $\mathrm{E}$ responses that was present only in $\mathrm{S}$ pigs $(\mathrm{r}=0.51, P<0.01)$. Correlation analysis also indicated positive relationships between the duration of the E response with the duration of exposure to IL-1 $\beta$, IL-6, and interferon gamma following LPS ( $\mathrm{r}=0.61,0.52$ and 0.48 ; respectively; $P<0.01$ ), regardless of maternal treatment. However, there was no relationship $(P>0.05)$ between the duration of exposure to $\mathrm{E}$ and the duration of TNF- $\alpha$ following LPS. The duration of NE response following LPS was also found to be positively related to the duration of all of the proinflammatory cytokines measured in this study $(\mathrm{r}=0.34,0.45,0.49$, and 0.48 for TNF- $\alpha$, IL- $1 \beta$,
Table 1

Effect of LPS challenge on WBC counts.

\begin{tabular}{lcccc}
\hline \multicolumn{5}{c}{ Time (h post-LPS) } \\
\hline Item $\left(\times 10^{3} / \mu \mathrm{L}\right)$ & 0 & 5 & 24 & SEM \\
WBC & $15.06^{\mathrm{a}}$ & $5.28^{\mathrm{b}}$ & $18.56^{\mathrm{c}}$ & 0.50 \\
Monocytes & $1.30^{\mathrm{a}}$ & $0.13^{\mathrm{b}}$ & $1.05^{\mathrm{c}}$ & 0.05 \\
Lymphocytes & $6.62^{\mathrm{a}}$ & $0.84^{\mathrm{b}}$ & $6.80^{\mathrm{c}}$ & 0.15 \\
Neutrophils & $6.69^{\mathrm{a}}$ & $4.28^{\mathrm{b}}$ & $9.76^{\mathrm{c}}$ & 0.43 \\
Basophils & $0.19^{\mathrm{a}}$ & $0.02^{\mathrm{b}}$ & $0.18^{\mathrm{a}}$ & 0.01 \\
Eosinophils & $0.24^{\mathrm{a}}$ & $0.02^{\mathrm{b}}$ & $0.73^{\mathrm{c}}$ & 0.02 \\
\hline Values within a row with different superscripts differ, $P<0.01$.
\end{tabular}

Values within a row with different superscripts differ, $P<0.01$.

IL-6, and interferon gamma, respectively; $P<0.05$ ). However, these relationships were only present in NS pigs, and there were no relationships between the duration of $\mathrm{NE}$ and the proinflammatory cytokines in $\mathrm{S}$ pigs. There were no relationships found between the duration of the proinflammatory cytokine response and the cortisol response following LPS regardless of maternal treatment.

\subsection{Leukocyte counts}

Mean white blood cell (WBC) count prior to LPS infusion $(0 \mathrm{~h})$ was $15.06 \pm 0.49 \times 10^{3}$ cells $/ \mu \mathrm{L}$ and was similar $(P=0.57)$ in both maternal treatments. As expected, lymphocytes and neutrophils comprised $>$ $88 \%$ of the total WBC present in peripheral circulation, with monocytes, eosinophils, and basophils making up the remaining $11 \%(8.6 \%, 1.3 \%$, and $1.6 \%$, respectively; Table 1). Lipopolysaccharide induced an initial redistribution of leukocytes out of circulation into tissues, followed by proliferation-induced increases in leukocyte numbers. The initial redistribution of leukocytes in response to LPS was reflected by an approximate $65 \%$ decrease in circulating WBC by $5.5 \mathrm{~h}$ postLPS $\left(15.06 \pm 0.5\right.$ vs. $5.28 \pm 0.5 \times 10^{3}$ cells $/ \mu \mathrm{L}$ at 0 vs. $5.5 \mathrm{~h}$, respectively) and was not affected by maternal treatment $(P>0.05)$. The redistribution was composed primarily of lymphocytes, which decreased by $87 \%$ $\left(6.62 \pm 0.15\right.$ vs. $0.84 \pm 0.15 \times 10^{3}$ cells $/ \mu \mathrm{L}$ at 0 vs. $5.5 \mathrm{~h}$, respectively) and to a quantitatively lesser extent by neutrophils, monocytes, basophils, and eosinophils, which decreased by $87 \%, 90 \%, 89 \%$, and $91 \%$, respectively.

Correlation analysis indicated negative relationships between the duration of exposure to TNF- $\alpha$, IL- $1 \beta$, IL-6, and interferon gamma with total WBC counts at $5.5 \mathrm{~h}(\mathrm{r}=-0.24,-0.32,-0.41$, and -0.42 , respectively; $P<0.05$ ), along with IL-1 $\beta$, IL-6, and interferon gamma with lymphocytes $(\mathrm{r}=-0.23,-0.20$, and -0.25 , respectively; $P<0.05$ ). Negative relationships between neutrophil number and serum TNF- $\alpha$, 


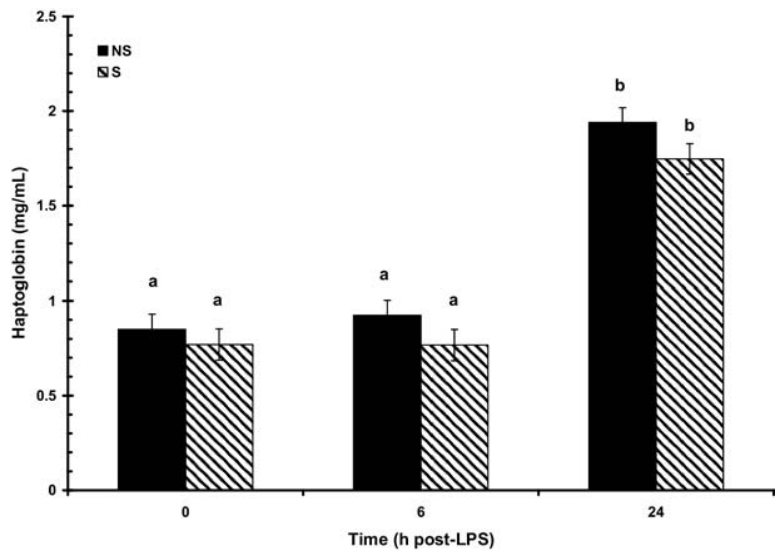

Fig. 8. Effect of maternal stress on the serum haptoglobin response of pigs to an intravenous challenge with $25 \mu \mathrm{g} / \mathrm{kg}$ LPS. Pigs were obtained from sows either subjected to a daily 5-min restraint stress (stressed; S) from days 84 to 112 of gestation or managed per current industry standards (nonstressed; NS). Values represent the mean \pm SEM (NS, $\mathrm{n}=39$; $\mathrm{S} \mathrm{n}=36$ ). Columns with different superscripts differ $(P<0.05)$.

IL-1 $\beta$, IL-6, and interferon gamma at $5.5 \mathrm{~h}$ post-LPS $(\mathrm{r}=-0.26,-0.31,-0.40$, and -0.42 , respectively; $P<0.05)$ were detected. There was also a negative relationship between the duration of exposure to IL-6 and monocyte count at $5.5 \mathrm{~h}$ post-LPS $(\mathrm{r}=-0.23, P<$ 0.05). Duration of exposure to the catecholamines (E and NE) was negatively associated with total WBC $(-0.30$ and -0.29 , respectively; $P<0.05)$, lymphocytes ( $\mathrm{r}=-0.30$ and -0.24 , respectively; $P<0.05$ ), and neutrophils $(\mathrm{r}=-0.27$ and -0.28 , respectively; $P<0.05)$. In addition, a negative relationship was detected between the duration of the $\mathrm{E}$ response and monocytes at $5.5 \mathrm{~h}$ post-LPS $(\mathrm{r}=-0.22, P<0.05$ ). There were no relationships between leukocyte counts at $5.5 \mathrm{~h}$ post-LPS and the duration of exposure to cortisol following LPS. Proliferation of leuckocytes was apparent at $24 \mathrm{~h}$ post-LPS as indicated by a $23 \%$ increase in WBC relative to numbers at $0 \mathrm{~h}$ (Table 1). Although there were increases in all WBC types, the quantitatively greatest increase occurred in neutrophils $\left(6.69 \pm 0.43\right.$ vs. $9.67 \pm 0.43 \times 10^{3}$ cells $/ \mu \mathrm{L}$ at 0 vs. $24 \mathrm{~h}$, respectively). Correlation analysis identified positive relationships between the duration of IL- $1 \beta$, IL-6, and interferon gamma responses with neutrophil count at $24 \mathrm{~h}(\mathrm{r}=0.34,0.28$, and 0.26 , respectively; $P<$ $0.05)$. Positive relationships were found between the duration of the E response and total WBC and neutrophils at $24 \mathrm{~h}$ post LPS $(\mathrm{r}=0.25$ and 0.41 , respectively; $P<0.05)$. There were no relationships $(P>0.05)$ found between the duration of the cortisol or NE re- sponses following LPS and the proliferation of leukocytes at $24 \mathrm{~h}$ post-LPS.

\subsection{Acute-phase proteins}

The APPs CRP, SAA, and haptoglobin were all detectable at low concentrations prior to LPS challenge at $0 \mathrm{~h}(108 \pm 13 \mu \mathrm{g} / \mathrm{mL}, 13 \pm 26 \mu \mathrm{g} / \mathrm{mL}$, and $0.81 \pm$ $0.05 \mathrm{mg} / \mathrm{mL}$, respectively) and were not affected by maternal treatment or sex $(P>0.05)$. Concentrations of all APP increased $(P<0.01)$ in response to LPS challenge. Increased $(P<0.01)$ serum haptoglobin concentration was apparent at $24 \mathrm{~h}$ post-LPS (Fig. 8). There was a main effect of treatment $(P<0.05)$ on haptoglobin response following LPS as a result of NS pigs having a consistently higher numerical concentration of haptoglobin at all time points compared with $\mathrm{S}$ pigs $(0.85 \pm 0.07$ vs. $0.77 \pm 0.08,0.92 \pm 0.07$ vs. $0.76 \pm .08$, and $1.94 \pm 0.07$ vs. $1.74 \pm 0.08 \mathrm{mg} / \mathrm{mL}$ for 0,6 , and $24 \mathrm{~h}$, respectively). However, maternal treatment did not affect $(P=0.77)$ the temporal pattern of haptoglobin response following LPS and there was no effect of sex $(P=0.99)$. Maternal treatment also influenced the SAA response to LPS $(P<0.05)$. An initial increase in SAA was apparent at $6 \mathrm{~h}$ post-LPS in $\mathrm{S}$ pigs and at $24 \mathrm{~h}$ in NS pigs (Fig. 9). At $24 \mathrm{~h}$ post-LPS $\mathrm{S}$ pigs had a higher $(P<0.01)$ concentration of SAA than NS pigs $(410 \pm 36$ vs. $546 \pm 37 \mu \mathrm{g} / \mathrm{mL}$, respectively). However, there was no influence of maternal treatment on the temporal pattern of SAA following LPS $(P=0.17)$. As with haptoglobin, there was no

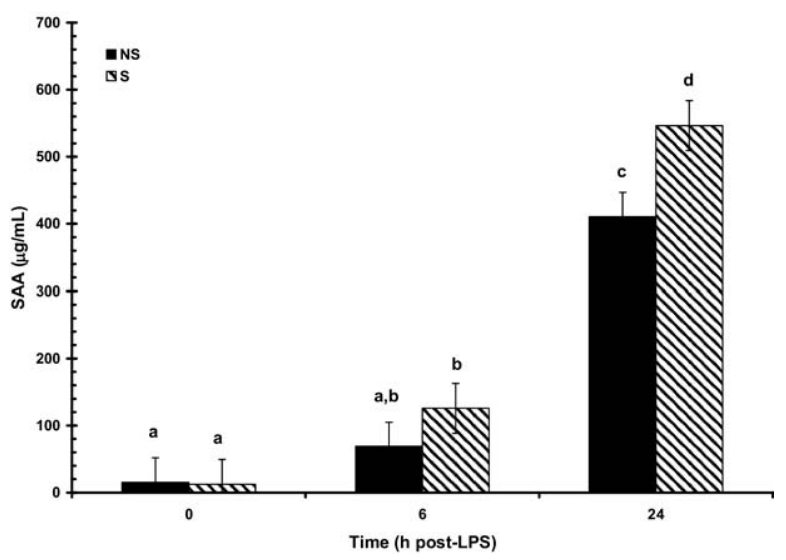

Fig. 9. Effect of maternal stress on the serum amyloid A (SAA) response of pigs to an intravenous challenge with $25 \mu \mathrm{g} / \mathrm{kg}$ LPS. Pigs were obtained from sows either subjected to a daily 5-min restraint stress (stressed; S) from days 84 to 112 of gestation or managed per current industry standards (nonstressed; NS). Values represent the mean \pm SEM (NS, $\mathrm{n}=39 ; \mathrm{S} \mathrm{n}=36)$. Columns with different superscripts differ $(P<0.05)$. 


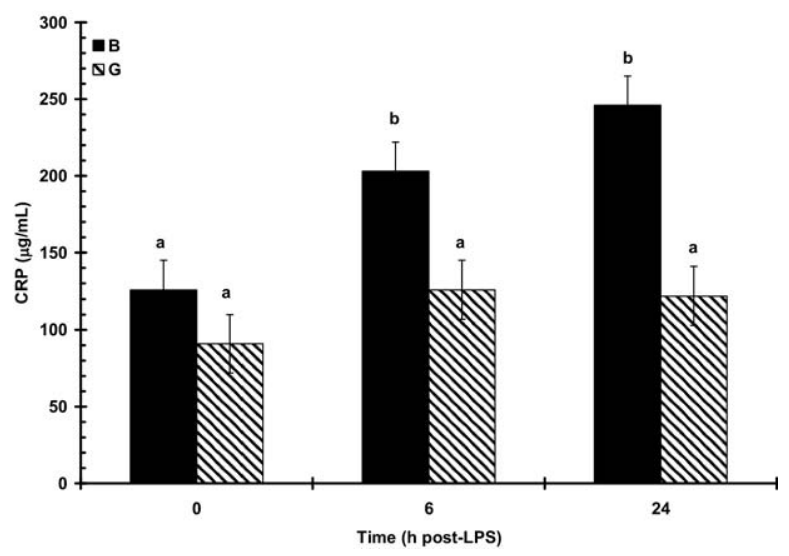

Fig. 10. Effect of maternal stress on the serum C-reactive protein (CRP) response of pigs to an intravenous challenge with $25 \mu \mathrm{g} / \mathrm{kg}$ LPS. Pigs were obtained from sows either subjected to a daily 5-min restraint stress (stressed; S) from days 84 to 112 of gestation or managed per current industry standards (nonstressed; NS). Values represent the mean \pm SEM (barrows, $\mathrm{B}, \mathrm{n}=40$, and gilts, $\mathrm{G}, \mathrm{n}=$ 37). Columns with different superscripts differ $(P<0.05)$.

effect of sex on the SAA response following LPS $(P=$ 0.82). In contrast to haptoglobin and SAA, the CRP response to LPS was not influenced by maternal treatment $(P=0.66)$, but was affected by the main effect of sex $(P<0.01)$. There was also a tendency for a maternal treatment $\times$ time interaction $(P=0.08$; Fig. 10). The basal concentration $(0 \mathrm{~h})$ of CRP did not differ between the sexes $(P=0.20 ; 126 \pm 19$ and $91 \pm 19$ $\mu \mathrm{g} / \mathrm{mL}$ for $\mathrm{B}$ and $\mathrm{G}$, respectively). However, by $6 \mathrm{~h}$ post-LPS there was an increase $(P<0.01)$ in serum concentration of CRP in B that remained at $24 \mathrm{~h}$ postLPS, whereas there was no increase $(P>0.05)$ in serum CRP in G following LPS.

Correlation analysis indicated positive relationships between the duration of the TNF- $\alpha$, IL-6, and interferon gamma responses and the concentration of SAA at $24 \mathrm{~h}$ post-LPS $(\mathrm{r}=0.54,0.55$, and 0.56 , respectively; $P<$ $0.05)$ that were not influenced by maternal treatment. A positive relationship was also present between IL-1 $\beta$ and $24 \mathrm{~h} \mathrm{SAA}(\mathrm{r}=0.43 ; P<0.01)$ in NS pigs, but this relationship was not significant in $\mathrm{S}$ pigs $(P>0.05)$. Because all three APP measured in this study are type I APPs, the lack of relationships between IL- $1 \beta$ with CRP and haptoglobin was unexpected. Correlation analysis also indicated positive relationships between the duration of the NE response with $24 \mathrm{~h} \mathrm{SAA}(\mathrm{r}=$ $0.58, P<0.05)$ and between NE and $24 \mathrm{~h}$ CRP ( $\mathrm{r}=$ $0.31, P<0.05$ ) in NS pigs, whereas these relationships were not significant in $S$ pigs. Interestingly, there were negative relationships found between the duration of $\mathrm{E}$ response in S pigs with $24 \mathrm{~h}$ haptoglobin $(\mathrm{r}=-0.38$, $P<0.05$ ). There were no relationships found between the duration of cortisol response with $24 \mathrm{~h}$ APP production regardless of maternal treatment.

\section{Discussion}

Previous reports on the effects of maternal stress in pigs have found that maternal stress is capable of influencing the cellular and humoral branches of the immune system in offspring [5]. Although the temporal pattern and the duration of exposure to the proinflammatory cytokines remained unaffected, maternal treatment did influence the magnitude of the TNF- $\alpha$ and IL-6 response to LPS. The TNF- $\alpha$ response also suggests that the effects of maternal stress can be gender specific.

Collectively, the data indicate that maternal stress is capable of altering both basal and post-LPS concentrations of inflammatory cytokines and stress hormones in offspring. The temporal patterns of TNF- $\alpha$ and IL- $1 \beta$ response to LPS found in this study are similar to that in previous reports on LPS response in pigs [10-12]. Similarly, the temporal patterns of IL-6, interferon gamma, cortisol, and catecholamines in this study are similar to those reported elsewhere [12-15]. These results are also consistent with previous reports on the effects of maternal stress on the offspring's stress response in both rats and pigs [2,6-19]. The increased basal concentration of cortisol in S pigs found in this study is similar to that in studies in rats that reported higher basal ACTH and corticosterone concentrations in stressed compared with nonstressed animals [16, 19,20]. However, the decreased concentration of cortisol in S B is in contrast to reports by Henry et al [17] and Takahashi and Kalin [16], who reported increased corticosterone response to stressors in maternally stressed rats, and Haussmann et al [2], who reported increased cortisol response to mixing stress in maternally stressed pigs. These contradicting reports may reflect differences in the type of stressor (immune challenge vs. acute physical stressors) because stressorspecific patterns of stress hormones have been documented (reviewed in [21]).

The gender effects elucidated in this study are consistent with our previous results [8]. The lack of maternal treatment influence on the $\mathrm{S} G$ cortisol response to LPS is supported by a previous report that showed the same lack of maternal stress influence on cortisol response to LPS in female offspring [22]. This result is further supported by correlation analysis that indicated 
a negative relationship between the magnitude of the $\mathrm{NE}$ and cortisol response in $\mathrm{S}$ pigs. The $\mathrm{S} \mathrm{B}$ had a higher magnitude of NE, which was then followed by a lower magnitude of cortisol response, whereas S G had a lower magnitude of $\mathrm{NE}$ response and maintained a normal cortisol response. To our knowledge, there are no reports describing the effects of maternal stress on the $\mathrm{E}$ response to stressors. The increased concentration of $\mathrm{E}$ in $\mathrm{S} \mathrm{B}$, however, is supported by correlation analysis showing a positive relationship between $\mathrm{NE}$ and $\mathrm{E}$ production. Increased $\mathrm{NE}$ in $\mathrm{S} \mathrm{B}$ could result in increased $\mathrm{E}$ in $\mathrm{S} B$ because peak production of $\mathrm{NE}$ occurs before peak E. We have shown that the temporal pattern of stress hormone response to LPS was not influenced by maternal treatment. This is supported by data from Takahashi and Kalin [16], who found that although maternally stressed rats had increased levels of ACTH and corticosterone in response to stress, there was not an effect of maternal treatment on the temporal pattern in response to stress.

The lack of a discernable correlation between the proinflammatory cytokines and cortisol observed here contrasts the premise that the proinflammatory cytokines feed back at the level of the hypothalamus to promote the production of cortisol (reviewed in $[23,24])$. However, the positive relationship between the catecholamines and IL- 6 production is supported by previous literature indicating that catecholamines can induce the production of IL- 6 in systemic circulation (reviewed in [25]). Furthermore, the positive relationships between catecholamine production and the proinflammatory cytokine production are consistent with in vitro and in vivo evidence indicating that the catecholamines can modulate (enhance or inhibit) the response of immune cells to antigenic challenge [26,27].

Consistent with previous observations and with reports from a number of other species, LPS induced an initial redistribution of leukocytes out of circulation into tissues, followed by proliferation-induced increases in leukocyte numbers [28-30]. These results agree with previous reports on the ability of LPS or live E. coli to induce a rapid redistribution of lymphocytes and monocytes out of peripheral circulation [28-30]. The negative relationships between catecholamine production and leukocyte counts at $5.5 \mathrm{~h}$ post-LPS suggest that the catecholamines are involved in inducing the redistribution of leukocytes. This is supported by reports that acute stress or administration of catecholamines is capable of inducing redistribution of leukocytes [26,27] and immune cell proliferation through activation of Th cells [31,32]. This is further supported here by correlation analysis suggesting positive relationships between the duration of IL- $1 \beta$, IL-6, and interferon gamma responses with neutrophil count at $24 \mathrm{~h}$ and consistent with their role in an immune response [33,34]. The results presented here are also consistent with the ability of proinflammatory cytokines to induce APP production [34,35]. Specifically, TNF- $\alpha$ and IL- $1 \beta$ induce the production of type I APP and IL- 6 to synergistically enhance this effect [36,37]. However, the lack of correlation between cortisol and 24-h APP production was unexpected because cortisol synergistically enhances the production of APP during an immune response (reviewed in [33,34]). The data presented here suggest that catecholamine production is capable of influencing APP production. To our knowledge these are the first reports on the presence of these relationships.

These data indicate that maternal stress changes typical proinflammatory cytokine and stress hormone response profiles of offspring, resulting in altered responses to LPS infusion, and that these changes can be influenced by gender. Specifically, immune and stress responses of $\mathrm{B}$ from $\mathrm{S}$ sows appear to be impacted more when compared with their $\mathrm{G}$ counterparts and B from NS sows. These data highlight the importance of managing the stress of pregnant sows to promote immune and stress responses in their offspring that are conducive for optimal production. These results also suggest a potential epigenetic stress response mechanism whereby subsequent generations are primed for handling particularly persistent environmental stressors that impact across multiple generations. The gender-specific nature of these epigenetic modifications also highlights the future need to describe their physiological relevance across generations to the respective genders. As such, because the pig is a viable model for human studies, these data also have important implications for human mothers and the health of their offspring.

\section{References}

[1] Lay DC, Jr Randel RD, Friend TH, et al. Effects of prenatal stress on suckling calves. J Anim Sci 1997;75:3143-51.

[2] Haussmann MF, Carroll JA, Weesner GD, Daniels MJ, Matteri RL, Lay DC Jr. Administration of ACTH to restrained, pregnant sows alters their pigs' hypothalamic-pituitary-adrenal (HPA) axis. J Anim Sci 2000;78:2399-411.

[3] Otten W, Kanitz E, Tuxhscherer M, Nurnberg G. Effects of prenatal restraint stress on hypothalamic-pituitary-adrenocortical and sympatho-adrenomedullary axis in neonatal pigs. $\mathbf{J}$ Anim Sci 2001;73:279-87.

[4] Klemcke HG. Placental metabolism of cortisol at mid- and late gestation of swine. Biol Reprod 1995;3:1293-301. 
[5] Tuchscherer M, Kanitz E, Otten W, Tuchscherer A. Effects of prenatal stress on cellular and humoral immune responses in neonatal pigs. Vet Immunol Immunopathol 2002;86:195-203.

[6] von Hertzen LC. Maternal stress and T-cell differentiation of the developing immune system: possible implications for the development of asthma and atopy. J Allergy Clin Immunol 2002;109:923-8.

[7] Burdick NC, Banta JP, Neuendorff DA, et al. Interrelationships among growth, endocrine, immune and temperament parameters in neonatal Brahman calves. J Anim Sci 2009;87:3202-10.

[8] Williams PN, Collier CT, Carroll JA, Welsh TH Jr, Laurenz JC. Temporal pattern and effect of sex on lipopolysaccharide-induced stress hormone and cytokine response in pigs. Domest Anim Endocrinol 2009;37:139-47.

[9] Carroll JA, Daniel JA, Keisler DH, Matteri RL. Non-surgical catheterization of the jugular vein in young pigs. Lab Anim 1999;33:1-6.

[10] Carroll JA, Gaines AM, Spencer JD, et al. Effect of menhaden fish oil supplementation and lipopolysaccharide exposure on nursery pigs I. Effects on the immune axis when fed diets containing spray-dried plasma. Domest Anim Endocrinol 2003; 24:341-51.

[11] Carroll JA, Gaines AM, Allee GL. Immunity in Swine: An Overview of Nutritional Modulation of the Acute Phase Response. Proceedings of the Prince Agri Products, Inc Twentyfifth Annual Feed Ingredient Conference, Kansas City, MO, August 31, 2005.

[12] Frank JW, Carroll JA, Allee GL, Zannelli ME. The effects of thermal environment and spray-dried plasma on the acute-phase response of pigs challenged with lipopolysaccharide. J Anim Sci 2003;81:1166-76.

[13] Carroll JA, Carter DB, Korte SW, Prather RS. Evaluation of the acute phase response in cloned pigs following a lipopolysaccharide challenge. Domest Anim Endocrinol 2005;29:564-72.

[14] Webel DM, Fink BN, Baker DH, Johnson RW. Time course of increased plasma cytokines, cortisol, and urea nitrogen in pigs following intraperitoneal injection of lipopolysaccharide. J Anim Sci 1997;75:1514-20.

[15] Wright KJ, Balaji R, Hill CM, Dritz SS, Knoppel EL, Minton JE. Integrated adrenal, somatotropic, and immune responses of growing pigs to treatment with lipopolysaccharide. J Anim Sci 2000;78:1892-9.

[16] Takahashi LK, Kalin NH. Early developmental and temporal characteristics of stress-induced secretion of pituitary-adrenal hormones in prenatally stressed rat pups. Brain Res 1991;558: $75-8$.

[17] Henry C, Kabbaj M, Simon J, LeMoal M, Maccari S. Prenatal stress increases the hypothalamo-pituitary-adrenal axis response in young and adult rats. J Neruroendocrinol 1994;6: $341-5$.

[18] McCormick CM, Smythe JW, Sharma S, Meaney MJ. Sexspecific effects of prenatal stress on hypothalamic-pituitaryadrenal responses to stress and brain glucocorticoid receptor density in adult rats. Brain Res Dev Brain Res 1995;84:55-61.

[19] Weinstock M, Poltyrev T, Schorer-Apelbaum D, Men D, McCarty R. Effect of prenatal stress on plasma corticosterone and catecholamines in response to footshock in rats. Physiol Behav 1998;64:439-44.

[20] Fameli M, Kitraki E, Stylianopoulou F. Effects of hyperactivity of the maternal hypothalamic-pituitary-adrenal (HPA) axis during pregnancy on the development of the HPA axis and brain monoamines of the offspring. Int J Dev Neurosci 1994;12: 651-9.

[21] Pacak K, Palkovits M. Stressor specificity of central neuroendocrine responses: implications for stress disorders. Endocrine Rev 2001;22:502-48.

[22] De Groot J, Kranendonk G, Fillerup M, et al. Response to LPS in female offspring from sows treated with cortisol during pregnancy. Physiol Behav 2007;90:612-8.

[23] Sapolsky RM, Romero LM, Munck AU. How do glucocorticoids influence stress responses? Integrating permissive, suppressive, stimulatory, and preparative actions. Endocr Rev 2000;21:55-89.

[24] Haddad JJ, Saade NE, Safieh-Garabedian B. Cytokines and neuro-immune-endocrine interactions: a role for hypothalamic-pituitary-adrenal revolving axis. J Neuroimmunol 2002;133:1-19.

[25] Charmandari E, Tsigos C, Chrousos G. Endocrinology of the stress response. Annu Rev Physiol 2005;67:259-84.

[26] Dhabhar FS. Stress-induced augmentation of immune function-the role of stress hormones, leukocyte trafficking, and cytokines. Brain Behavior Immun 2002;16:785-98.

[27] Elenkov IJ, Wilder RL, Chrousos GP, Vizi ES. The sympathetic nerve-an integrative interface between two supersystems: the brain and the immune system. Pharmacol Rev 2000;52:595638.

[28] Willette AA, Lubach GR, Coe CL. Environmental context differentially affects behavioral, leukocyte, cortisol, and interleukin-6 responses to low doses of endotoxin in the rhesus monkey. Brain Behavior Immun 2007;21:807-15.

[29] Gehad AE, Lillehoj HS, Hendricks GL, III Mashaly MM. Initiation of humoral immunity. II. The effects of T-independent and T-dependent antigens on the distribution of lymphocyte populations. Dev Comp Immunol 2002;26:761-71.

[30] Trout JM, Mashaly MM, Siegel HS. Changes in blood and spleen lymphocyte populations following antigen challenge in immature chickens. Br Poult Sci 1996;37:819-27.

[31] Elenkov IJ, Chrousos GP. Stress hormones, Th1/Th2 patterns, pro/anti-inflammatory cytokines and susceptibility to disease. TEM 1999;10:359-68.

[32] Mossmann TR, Sad S. The expanding universe of T-Cell subsets: Th1, Th2 and more. Immunol Today 1996;17:138-46.

[33] Baumann H, Gauldie J. The acute phase response. Immunol Today 1994;15:74-80.

[34] Pettersen HH, Neilsen JP, Heegaard PMH. Application of acute phase protein measurements in veterinary clinical chemistry. Vet Res 2004;35:163-87.

[35] Suffredini AF, Fantuzzi F, Badolato R, Oppenheim JJ, O'Grady NP. New insights into the biology of the acute phase response. J Clin Immunol 1999;19:203-14. 